УДК 001+101.1:316

DOI: $10.21779 / 2500-1930-2017-32-3-27-31$

\title{
С.3. Семерник
}

\section{Социально-экономическая модернизация в глобальном мире: опыт мир-системного анализа ${ }^{1}$}

Учреждение образования «Гродненский государственный университет им. Янки Купальı»; Республика Беларусь, 230023, г. Гродно, ул. Ожешко, 22; semernik@grsu.by

В статье на методологической основе мир-системного подхода дан анализ современных социально-экономических преобразований, затрагивающих не только отдельные регионы планеты, но и мир в целом. Показана системность происходящих трансформаций, указывающая на взаимовлияние и взаимозависимость модернизационных процессов, реализуемых на уровне различных стран. Обосновано положение о том, что современное мировое сообщество отличает неравномерность развития отдельных регионов. Данная неравномерность является результатом формирования и развития такого типа мировой экономики, который предполагает доминирование виртуального, финансового сектора над реальным производством. Установление такого типа приоритетов в системе получения прибыли в свою очередь способствует возникновению феномена долговой экономики, основанной на кредитных деньгах. Сложившаяся ситуация предполагает неравномерное распределение экономических статусов между субъектами хозяйственной деятельности. Одни субъекты хозяйственной деятельности, имеющие возможность выступать в качестве эмитентов и кредиторов по отношению к другим, находятся в заведомо более выгодном положении, со временем лишь укрепляя статус доминирующих в экономическом, а также политическом и культурном отношении акторов. Данная ситуация неравенства нуждается в переосмыслении, нахождении путей выхода из создавшегося положения стран, находящихся в статусе перманентных должников.

Ключевые слова: мир-системный подход, модернизащия, экономика, общество, капитализм.

Для серьезного научного анализа происходящих в современном обществе процессов необходимо четко сориентироваться в методологическом корпусе теоретических подходов, с позиций которых предлагается осуществлять изучение искомого предмета. Данная проблема - поиск адекватной задачам и предмету исследования методологии на сегодняшний день чрезвычайно актуальна, поскольку общепризнанная в современной философии и науке установка на методологический плюрализм увеличивает гносеологическую ответственность познающего субъекта, т. к. он вынужден действовать в ситуации выбора. Ситуация выбора некоторой методологической посылки указывает на конструктивистский характер всякого научного изыскания, когда исследователь не просто «анализирует», «раскрывает», «выявляет» некоторые данности и закономерности, а задает их логикой методологических предпочтений.

Как справедливо замечает российский культуролог И.Г. Яковенко, «...идеальный исследовательский принцип состоит в том, что выбирается такая система методов, ко-

\footnotetext{
${ }^{1}$ Статья подготовлена по материалам доклада, представленного на III Международной научнопрактической конференции «Модернизация экономических систем: опыт и перспективы», которая прошла 27-28 апреля 2017 года в Дагестанском государственном университете (г. Махачкала, РФ).
} 
торая отвечает специфике самого исследуемого объекта. Здесь метод задается природой объекта» [1, с. 6].

Проблему современных социально-экономических модернизаций можно рассматривать в контексте различных методологических подходов: использовать классические наработки формационного подхода, эвристический потенциал цивилизационного анализа, синергетический подход и т. п., что является очевидным для большинства современных исследователей $[2,3,4,5]$. На наш взгляд, адекватное понимание происходящих в обществе модернизаций можно сформировать, используя теоретические основания мир-системного анализа.

Мир-системный подход сложился во 2-й половине XX в. и представлен такими авторами, как С.Г. Франк, Ф. Бродель, И. Валлерстайн, С. Амин, Дж. Арриги, А.И. Фурсов и др. Суть его заключается в признании существования взаимосвязывающей все общества мир-экономики, благодаря наличию которой говорить о социальноэкономическом развитии отдельных стран вне рассмотрения их локус-позиции относительно других стран неправомерно.

Достоинство данного подхода состоит в том, что он рассматривает социальные изменения не на уровне отдельно взятых обществ, а системно - в совокупности локальных социумов. Данная методологическая установка представляется вполне оправданной и актуальной для современного этапа развития социума, поскольку нарастание в мире глобализационных тенденций, направленных на усиление взаимосвязи и взаимозависимости стран и даже целых континентов, со всё большей очевидностью указывает на необходимость выявления характера данной взаимосвязи и принципов взаимозависимости. Чтобы разобраться в сути данных отношений, необходимо понять, на каких экономических основаниях они строятся. Здесь можно отметить следующие особенности.

Наиболее яркой чертой, характерной для современной социоэкономической динамики выступают активное «обиржевание» (В. Зомбарт) экономики, усиление финансового капитала и банковского сектора над промышленным. В результате современная экономика представляет собой модель долговой экономики, основанной на кредитных деньгах, главное назначение которых состоит не столько в том, чтобы быть эффективным инструментом обмена, активизируя экономическое взаимодействие на рынке, сколько в обеспечении механизма установления зависимостей одних субъектов хозяйствования от других (зависимость реального сектора экономики от фиктивного финансового). Не удивительно, что сегодня активно увеличивается количество должников среди субъектов хозяйствования самых различных уровней. Таковыми становятся не только отдельные предприятия, но и экономика целых государств. Причем тенденция роста государственных долгов продолжает расти, поскольку при реализации долговой модели экономики запуск обратных процессов практически невозможен: отсутствуют реальные экономические (и политические) инструменты для решения данной проблемы.

Результатом закрепления в обществе долговой модели экономики, основанной на легитимации господства глобального фиктивного капитала, может быть движение стран, вовлеченных в данную систему политико-экономических отношений, в сторону десуверенизации. При этом утрату суверенности можно ожидать не только в сферах экономики, образования, политики, науки, но и в культурной сфере.

Возникает закономерный вопрос, по какому принципу распределяются мировые кредиторы и должники глобальной мир-системы? Ответ на данный вопрос можно найти, рассмотрев концепцию «развития отсталости» американского экономиста Адре Гюндера Франка [6]. Согласно теории А.Г. Франка, отсталость так называемых «третьих стран» является не естественной причиной их развития, а искусственно насаждае- 
мым феноменом. Конструирование принципов развития таких стран, обрекающих их на безнадежность периферийного развития, является неотъемлемым условием процветания других стран, выступающих в качестве центра мировой капиталистической системы. Мировое разделение труда по принципу сосредоточения в одних зонах мира капиталоемких производств, позволяющих извлекать максимальную прибыль, и трудоемких, чрезвычайно трудозатратных, но с низкой долей получения прибыли в других приводит к тому, что страны, которым досталась участь низкоприбыльного, но многозатратного труда, стремительно отстают в своем развитии от своих конкурентов, специализирующихся на капиталоемких производствах. Именно в «третьи» страны переносятся трудозатратные виды деятельности, а все капиталоемкие производства и технологии сосредоточены в наиболее богатых странах ядра мировой капиталистической системы. И это только один из факторов искусственного разделения стран на «центр», «полупериферию» и «периферию» мирового развития.

Российский экономист Р.С. Дзарасов пишет: «Большинство стран Азии, Африки и Латинской Америки к моменту вторжения в их жизнь капитализма были развитыми для своего времени обществами, обладавшими диверсифицированными экономиками и относительной социальной стабильностью. Попав в сферу колониальной эксплуатации, эти общества подвергались глубокой трансформации, которая затронула как их производительные силы, так и общественные отношения. Экономикам колоний навязывался монокультурный характер, т. е. многообразие их хозяйственной деятельности сводилось к нескольким основным трудозатратным производствам, ориентированным на потребности метрополий. Одновременно трансформировалась и социальная структура этих стран. Крестьянство лишали доступа к земле и, навязав массовую бедность, под угрозой голода создавали армию дешевого труда для трудозатратных производств. Одновременно изменялся и правящий класс колонизированных стран. В его среде взращивалась компрадорская буржуазия, выступавшая в роли посредника в эксплуатации природных и трудовых ресурсов своих стран в интересах метрополий» [7].

Таким образом, модернизация и соответствующая трансформация производительных сил и производственных отношений в современном глобальном мире не всегда осуществляются по пути улучшения данных отношений. Существует модернизация, направленная на возвышение одних стран в ущерб развития других. Данный механизм, получивший название «насаждение отсталости», реализуется через такое мировое разделение труда, когда в обреченных на отставание странах внедряются путем модернизации трудозатратные технологии, происходят пауперизация широких слоев населения и значительное снижение уровня социальных отношений, что выражается в экспоненциальном росте расслоения между богатыми и бедными. В то время как страны «ядра» капиталистической системы получают дешевые товары и аккумулируют в своих руках крупный капитал.

Исходя из вышесказанного можно заключить, что странам, которые не желают быть причастными отсталой периферии мирового развития, необходимо двигаться по пути создания высокотехнологичных капиталоемких производств, поставляя на мировой рынок товары с высокой добавленной стоимостью. Об этом сегодня всё чаще пишут не только экономисты, но и политики, представители культуры $[8,9,12,13]$.

Для реализации названной задачи необходимо трансформировать не только экономические отношения в обществе, но и саму социокультурную сферу. В частности, необходимо на достаточно высоком уровне развивать систему образования и науки, благодаря кадровому и идейному потенциалу которых могут быть разработаны и внедрены в реальный сектор экономики высокотехнологичные производства. Снижение 
уровня образования является рискогенной ситуацией для развития современного социума, поскольку она не только затрудняет воспроизводство существующей социальноэкономической инфаструктуры, но и делает невозможным прогрессивное развитие экономики на основе высокотехнологичного наукоемкого производства. Особенно актуальна данная проблема для стран, относящихся на сегодняшний день к «периферии» мирового развития. Инвестиции в сферу образования и науки являются косвенными инвестициями в развитие социальной сферы и экономики. Можно заключить, что преодоление нарастающего разрыва в социально-экономическом развитии между странами является комплексной задачей, требующей совокупного применения как собственно экономических, так и неэкономических методов и подходов. Только лишь целостный подход к проблемам развития, позволяющий рассматривать экономику отдельной страны как локальную культурно-хозяйственную систему, гибко встроенную в общемировую систему, может выявить и предложить необходимые пути решения накопившихся проблем.

\section{Литература}

1. Яковенко И.Г. Познание России: цивилизационный анализ. - 2-е изд., перераб. и доп. - М.: Российская политическая энциклопедия (РОССПЭН), 2012. - 671 с.

2. Бабосов Е.М., Кирвель Ч.С., Романов О.А. Современный социум: характер и направленность развития. - Минск: Четыре четверти, 2013. - 728 с.

3. Болдырев И. Никлас Луман и экономическая наука // Экономическая социология. -2011 . - Т. 12, № 1. - С. 25-42.

4. Сидорина T.Ю. Российское общество в контексте тенденций мирового общественного развития // Мир России. - 2017. - № 2. - С. 128-153.

5. Мохов А.И. Модели «новой теории экономических систем» в условиях применения комплексного подхода // Вестник РАЕН. - 2016. - Т. 16, № 2. - С. 69-75.

6. Frank $A$. The development of underdevelopment // Monthly review. - 1966. Vol. 18, № 4. - P. 17-31.

7. Дзарасов P.C. Национальный капитализм: развитие или насаждение отсталости? - [Электронный ресурс]. - Режим доступа: http://www.intelros.ru/readroom/alternativi/a1-2013/19020-nacionalnyy-kapitalizm-razvitieili-nasazhdenie-otstalosti.html. - Дата доступа: 12.04.2017.

8. Альпидовская М.Л. Три фундаментальных вопроса экономики и неизбежность их решения в современной России // Теоретическая экономика. - 2013. - № 5 (17) C. $8-13$.

9. Бендиков М.A., Хрусталев О.Е. Механизм инновационного развития наукоемких высокотехнологичных производств и рынков // Экономический анализ: теория и практика. - 2012. - № 28. - С. 2-13.

10. Аскеров Н.С. Модернизация институтов в посткризисной экономике // Вопросы структуризации экономики. - 2011. - № 1. - С. 23-27.

11. Аскеров Н.С. Модернизация институтов традиционной культуры как фактор развития кризисной территории // Вестник Московского государственного университета культуры и искусств. - 2014. - № 2 (58). - С. 69-75.

12. Бодрунов С.Д. Новое индустриальное общество второго поколения: человек, производство, развитие // Общество и экономика. - 2016. - № 9. - С. 5-21.

13. Глазьев С.Ю. Стабилизация валютно-финансового рынка как необходимое условие перехода к устойчивому развитию // Экономика региона. - 2016. - Т. 12, № 1. C. 28-36.

Поступила в редакциию 5 июля 2017 г. 
UDC 001+101.1:316

DOI: $10.21779 / 2500-1930-2017-32-3-27-31$

\section{Socio-economic modernization in the global world: the experience of world-system analysis}

\section{S.Z. Semernik}

Faculty of Education the educational institution «Grodno State University named after Yanka Kupala», Republic of Belarus, 230023, z. Grodno,Ozheshko st., 22; semernik@grsu.by

The analysis of modern socio-economic transformations affecting not only certain regions of the planet but the world as a whole is given on the methodological basis. The systemic nature of the transformations, indicating the mutual influence and interdependence of modernization processes implemented at the level of different countries is shown. The position is grounded on the fact that the modern world community is distinguished by the uneven development of individual regions. This misbalance is the result of the formation and development of this type of world economy, which assumes the dominance of the virtual, financial sector over real production. The establishment of this type of priority in the system of profit making, in its turn, contributes to the emergence of the phenomenon of debt economy, based on credit money. The current situation presupposes uneven distribution of economic status among economic entities. Some business entities that have an opportunity to act as issuers and creditors in relation to others are in a much more advantageous position. Only strengthening the status of actors dominant in economic, political and cultural sectors is regarded as efficient. This situation of inequality requires rethinking, finding some ways out of the countries that are in the status of permanent debtors, from the situation that has arisen.

Keywords: world-system approach, modernization, economy, society, capitalism.

Received 5 July, 2017 